\title{
From One Culture to Another: Years One and Two of Graduate School for African American Women in the STEM Fields
}

\author{
Joretta Joseph \\ The National Physical Science Consortium, \\ Los Angeles, CA, USA \\ ¡bjoseph@usc.edu
}

\begin{abstract}
Historically Black Colleges and Universities (HBCUs) provide an educational pathway for many Black students, particularly women who seek graduate degrees. Despite the positive presence of HBCUs in the African American community, the academic training of students who graduate from HBCUs may be perceived as insufficient by Predominantly White Graduate Institutions (PWIs). As a result, African American students who are not well integrated into their respective departmental communities and cultures at PWIs are likely to leave graduate school. Research has also indicated that the first two years at a PWI is crucial for students of color. This study examines how students make the two-year transition from HBCU to majority institutions and what impact this transition has on their persistence and commitment to their discipline.
\end{abstract}

Keywords: African American Female Students, STEM, Historically Black Colleges and Universities (HBCUs), Predominantly White Institutions (PWIs), Graduate School, Graduate Students, Socialization, Transition

\section{Introduction}

Historically Black Colleges and Universities (HBCUs) have long been an intellectual resource for the African American community. HBCUs have provided and continue to provide an educational pathway for many African American students, particularly women who seek advanced degrees. From 2003 through 2007 seven of the top ten colleges that awarded bachelor's degree in the fields of Science, Technology, Engineering, and Mathematics (STEM) to African Americans were HBCUs (NSF, 2009a). In addition, the top ten baccalaureate institutions of doctoral degree recipients between 2003 to 2007 were all HBCUs (NSF, 2009b). Despite the overwhelmingly positive presence of HBCUs in the African American community, the academic training of students who graduate from HBCUs is often perceived as insufficient by Predominantly White Graduate Institutions (PWIs) and their faculty (Kim \& Conrad, 2006). As a result, African Amer-

Material published as part of this publication, either on-line or in print, is copyrighted by the Informing Science Institute. Permission to make digital or paper copy of part or all of these works for personal or classroom use is granted without fee provided that the copies are not made or distributed for profit or commercial advantage AND that copies 1 ) bear this notice in full and 2) give the full citation on the first page. It is permissible to abstract these works so long as credit is given. To copy in all other cases or to republish or to post on a server or to redistribute to lists requires specific permission and payment of a fee. Contact Publisher@InformingScience.org to request redistribution permission. ican students from HBCUs that move on to attend PWIs for graduate education may not be well integrated into their respective departmental communities and cultures, and may be perceived as less-skilled (Burgess, 1997; Kim \& Conrad, 2006). They are also likely to leave graduate programs within the key transition period of the first two years (Herzig, 2004; Tinto, 1993). 
HBCUs and majority White research institutions are known to exhibit cultural differences (Weidman, Twale, \& Stein, 2001). At HBCUs at the undergraduate level, associations and involvement are university-wide (across disciplines and respective academic units), and the culture is perceived to be open and encouraging from the time the students step on to campus (Perna, Lundy-Wagner, Drezner, Gasman, Yoon, Bose \& Gary, 2009; St. John, 2000). In contrast, PWIs have been described as places where faculty are indifferent, where little advice is offered, where students are expected to work independently, and where students associate almost exclusively within their respective departments (Morelle, 1996). Thus while HBCUs may provide the support and grounding that engages their students academically and launches their pursuit of higher degrees, they may not prepare them to meet the climate they face upon reaching their graduate programs.

To understand the fundamental characteristics of HBCUs and why they differ from PWIs, it is helpful to first consider the six goals that serve as their framework: 1) the maintenance of the Black culture and historical traditions; 2) the creation and retention of Black leadership within the HBCU; 3) the commitment to being an economic unit within the community in which each school respectively stands; 4) the creation of Black role models to interpret the dynamics that impact other Black people outside of the college community; 5) the creation of leaders that are confident and competent in their dealing with of issues that affect all people; and 6) the creation of change agents that can conduct research, training, and disseminate information benefiting everyday lives of all minority communities (Brown \& Davis, 2001). Although all HBCUs are not alike, their cultural traditions are such that they all intuitively enforce the belief that the goal of education should be couched in terms of social responsibility (Mays, 1942). HBCUs consider themselves "social agencies" and "social equalizers" for students of color that have been denied access to higher education and marginalized in society.

The purpose of this paper is to present the experiences of African American women who transition from HBCUs to majority institutions in STEM fields and what impact this transition has on their persistence and commitment to their disciplines. Specifically this article is the result of a case study inquiry focused on the experiences of six African-American female students who transition from undergraduate studies at HBCUs to graduate studies (during the first two years) in mathematics and chemistry at PWIs. I look at the assumption that successful undergraduate experiences at HBCUs-generally considered inviting and nurturing in terms of student support (Kim, 2002) — ensure success at the graduate school level, where a different culture may be found. This article contributes to the limited amount of research available that looks at the process of how a student adjusts to graduate school, on an individual and departmental level (Gardner, 2007; Ong, Wright, Espinosa, \& Orfield, 2011). The study focuses exclusively on the experiences of African American women, with the understanding that they face a unique set of challenges that are separate from factors that impact Euro-American women and men of color, who are also under-represented in the STEM fields (Leggon, 2003). The findings will present empirical data from the student's perspective while the ideas within the discussion and conclusion are those of the author.

\section{Socialization: The First Two Years of Graduate School}

Extant research that the first two years of graduate education are a key period of adjustment, as many students (minority and majority) who eventually drop out do so in year one or two of graduate school (Tinto, 1993). With an approximately 50 percent attrition rate for doctoral students in science and engineering and two-thirds of all Black students pursuing doctoral degrees not completing the degree (Bethea, 2005), the nation is losing an important resource of highly trained people. Some of the identifiable factors that contribute to student departure are program selection, 
lack of mentoring, issues with financial support, program environment, the research mode of the specific field entered, procedures involved in a particular field of study, and time or family commitments (McElfresh, 2005).

Graduate school is where students gain their professional identities. It is the outcome of the process of socialization - how new skills, beliefs, patterns of action, and at times, personal identities are acquired in a new setting (Van Maanen, 1983) - into their academic department and profession that determines their success as a science graduate student. Socialization, which is a three step process of acquiring the appropriate role behaviors of the department and discipline, the development of the appropriate skills and abilities, and the ability to adjust to the department's and discipline's values and norms (Feldman, 1981), is influenced by both academic and social factors. The academic factors for the students include academic and social relationships with faculty through mentoring and advising, as well as the relationships with peers. The social factors include the financial assistance available, as well as family support and motivation (Maton \& Hrabowski, 2004). The one factor that brings all of these together is the student's personal efforts and ability to grasp the skill and knowledge that is being presented (Amenikhienan \& Kogan, 2004). Simultaneously, the students in the study are also navigating between cultures. In the case of the women in this study the navigation includes their undergraduate experiences at HBCUs and their graduate experiences at PWIs as well as the culture of their discipline. It is also important to note that how a person progresses throughout this process is also a reflection of how the group, or individuals, within the new culture (department / discipline), accept the new person and his or her personal traits (Berry 1997; Ward, 1996).

In order to transition into graduate school successfully, a student needs to be able to navigate the context of her department and understand that departmental values and expectations-as well as grades - are influential in her achievement (Turner, 2002). External and internal policies, institutional values, traditions, and academic discipline all help determine the context of the department in which the student finds herself. Cultural influences, prior experiences, personalities, the persons external support system, along with the student's level of commitment also influences a student's progress through her graduate education (Ellis, 2001; Herzig, 2004).

This multitude of relationships and experiences may not have the same effect on or be perceived in the expected ways by students with different backgrounds (Weidman et al., 2001). For example, a study by Turner and Thompson (1993) explores the socialization process of 37 minority women doctoral students and 25 majority women doctoral students (though not exclusively in the STEM fields). The results of that study showed that the minority students had fewer professional socialization opportunities, while the social environment was richer for majority students. More majority students had greater mentoring and apprenticeship experiences. Under conditions of isolation, lack of advisement, or just plan indifference - as has been noted at PWIs -it takes strong commitment and discipline, and a high cognitive level, for a minority student to acquire the skills it takes to persist in her doctoral program (Hamilton, 2001). This article looks at the first 2 year transitional period of African American female graduate students who, due to differences in background and to their experiences at HBCUs, may not have a smooth transition, yet still found the ability to persist and succeed.

\section{Methodology}

This study allows the students' voices to be heard by the use of qualitative research methods. A case study approach is utilized in order to explore the individuals' attitudes, behaviors, and cultural identities. The study consists of six African American women within their first and second year of enrollment in a graduate program. The participants were initially identified via the database of the National Physical Science Consortium (NPSC). The NPSC is an organization that administers fellowships to persons seeking a $\mathrm{PhD}$ in mathematics, science, or engineering. I re- 
viewed the database of students who had applied for and received the fellowship within the last three years and identified perspective participants. I also spoke with a gatekeeper at a government agency (a Department of Energy Laboratory) about people within their organization who would be both willing to participate and good candidates for this study. I initially contacted thirty male and female persons via email, introduced myself and briefly described my study to them. Five female students responded within a two-week period, with an interest and willingness to participate. From the initial five respondents, I utilized snowball sampling techniques to secure an additional participant.

Table 1: Demographic and Educational Characteristics of Participants

\begin{tabular}{|l|l|l|l|l|l|}
\hline Name * & Age & $\begin{array}{l}\text { Undergraduate } \\
\text { Institution (UI)* }\end{array}$ & $\begin{array}{l}\text { Graduate } \\
\text { Institution } \\
\text { (GI)* }\end{array}$ & Discipline & $\begin{array}{l}\text { First Generation } \\
\text { College Student }\end{array}$ \\
\hline Keisha & 24 & UI-1 & Gl-1 & Mathematics & No \\
\hline Kerry & 22 & Ul-2 & GI-2 & Mathematics & Yes \\
\hline Shavanna & 24 & UI-3 & Gl-3 & Mathematics & No \\
\hline Paulette & 24 & Ul-4. & GI-4 & Chemistry & Yes \\
\hline Victoria & 26 & UI-5. & Gl-5 & Chemistry & No \\
\hline Rachelle & 23 & Ul-5 & Gl-6 & Mathematics & No \\
\hline
\end{tabular}

* Pseudonyms ** This study was approved by the University of Southern California Institutional Review Board (USC UPIRB \#UP-06-00039).

The study was conducted from January 2006 through August 2006. I utilized individual interviews, observations, my reflective notes, participant journals, and document analysis (including departmental brochures, handouts, college catalogues, and other published literature). I conducted four interviews with each of the six participating students. Each interview lasted approximately one hour with 15 to 20 questions being discussed during each interview. The multiple interview structure allowed the participants and me to check for any inconsistencies and make sense of what had been said (Seidman, 1998). Trust was built as a result of the multiple interviews, which yielded valuable information that not only benefited this study but also allowed the students to express thoughts and feelings that may not have come to the surface during a single interview.

Prior to the first interview, themes from the literature on the experiences of African American students at HBCUs and PWIs, as well as from socialization and acculturation theories, were used to construct the initial interview questions. Additional themes and questions were derived from the initial questions as the study advanced. A preliminary list of thematic codes was derived from the data and correlated with the women's personal attributes and background, their undergraduate and graduate experiences, any prior knowledge or research experiences in their chosen field of study, and their future plans (see Appendix).

In this paper I share commentary from the interviewees to provide insight into how the differences in culture between HBCUs and PWIs impacted their transitions to graduate school and situate their answers in the historical context of understood differences between HBCUs and other institutions of higher learning. I also discuss the factors that enabled these six students to perse- 
vere and succeed in spite of obstacles. The findings highlight eight aspects of the year-one and year-two transitional experience:

- sense of belonging and social responsibility

- faculty interactions at HBCUs

- self-image and identity

- the culture at PWIs

- $\quad$ interactions with faculty at PWIs

- $\quad$ interactions with peers at PWIs

- academic preparedness

- $\quad$ strategies for success

\section{Findings}

Although the women in this study share similar academic and professional backgrounds, each presents unique perspectives regarding life choices, professional interests, and academic experiences. They each faced multiple levels of acculturation related to gender, academic discipline, and race/ethnicity. While assuming their roles as graduate students, integrating themselves into both academic life and the scientific profession, and becoming members of a specific discipline, these students (of which two of the six students are first generation college students) also faced the challenge of purposefully transitioning between institutions of higher education that are traditionally and culturally very different.

\section{HBCUs - A Sense of Belonging and Social Responsibility}

Historically Black Colleges and Universities provide a developmentally powerful environment for students from the first time the student walks on to the campus. Orientation is even geared towards the development of a supportive culture amongst both peers and faculty (Perna et al., 2009). There is a community of faculty and staff that are invested in the students' well-being as part of a network that works to advance the opportunity of each student (Subramaniam \& Wyer, 1998). Students gain a sense of psychological well-being and cultural affinity, while nurturing academic and social relations that could last for many years beyond the college experience (Kim, 2002). Students at HBCUs tend to feel at home, like they are among family (Fries-Britt \& Turner, 2002). This sentiment was also expressed by Kerry when she said, "I loved it. I was highly involved; I did it all. I felt at home, it was a family atmosphere. People took me in and out. What ever I needed I got. You could be you and find a place instead of trying to fit in.” The students also believe that the faculty and staff go out of their way to assist them with their needs and provide support and encouragement (Fries-Britt \& Turner, 2002). Peer interactions are friendly with a far reaching sense of mutual support (Fries-Britt \& Turner, 2002).

The students in this study described the climates of their HBCUs in the following ways: "automatically comfortable, and I didn't feel out of place;" "the greatest feeling in the world. [I] No longer feeling out of place;" "I felt at home, it was a family atmosphere;" in addition to, "I felt like I had an impact and say in how the school was run.” The students also felt that they left their undergraduate institutions having been taught to believe in themselves and to think beyond their own circumstances. For Keisha she "realized that everyone is special and has their own place and their own uniqueness and so your differences should be something to celebrate." For Kerry this sense of social responsibility was ingrained in the classroom where an instructor "referred to us as intellectuals the whole semester. [From] the first day [he would say] you all have a social responsibility." Victoria commented, "I left my undergrad institution knowing that I must now do something using my education." This comment is in concert with a quote by WEB DuBois that "highlights the mandate for these institutions [HBCUs] to engage the world, improve the circumstances 
of Black people and challenge the nation to realize its highest ideals” (Allen, Jewell, Griffin \& Wolf, 2007, p. 263).

\section{Faculty Interactions at HBCUs - Hands On and Personal}

The faculty at HBCUs plays a major role in the success of the students. The diversity of the faculty at these institutions provides the student with role models that are readily available for oneon-one discussions. The literature notes that the interpersonal relationships between the students and faculty may be at the heart of what makes the difference in the academic success of the students due to faculty support, understanding, and their genuine concern that is displayed on a regular basis (AAUP, 1995; St. John, 2000). This is so important since at some HBCUs the faculty offices, particularly of STEM faculty, are situated so that the students may access them at any time (Perna et al., 2009). Kerry described her relationship with faculty members thus: "Once I expressed an interest in math and in graduate school my instructors wrote me a plan of action. They (the faculty) wrote a plan of action - they made sure that I attended conferences and they encouraged me to participate in research.”

These types of interactions between students and faculty members play a significant part in the students' participation in both academic and social organizations, student government, and their self-concept (Berger \& Milem, 2000). This ultimately has a positive effect on the student's academic success. The students in the study said that it was the faculty who noticed their talents, and that they not only encouraged them to attend graduate school but also opened doors for them that they could not have imagined. Like Kerry, Shavanna said, "There was faculty that noticed that I was serious, and they sought out opportunities to increase my knowledge and exposure to the field.” As Kerry's relationships with her faculty members grew they took her to conferences, encouraged her to participate in research, and really pushed her to go to graduate school.

They offered to take me to conferences and so I actually went on a conference for three days, a three-day trip to North Carolina with like two professors. This year, last semester, they asked me to come back and speak to the students, to the current math majors about my experiences thus far in graduate school. I went to a conference a couple of weeks ago, a huge math conference, and I met up with the professors who came. I had all of them before I went on a conference with them previously or I did research with them and so all of them were there and they really treat you and just talk to you, you know, as your equals as you become more familiar with them and have been in more than one of their classes you know they reach out to you and suggest things to you and you know guide you in any way.

These close interactions were also noted by an administrator at a HBCU who said, “You don't get as much teaching and hands-on care at other schools as you do at HBCUs. Our professors are involved with a lot more than research and teaching. We do some real close mentoring, for instance, that you don't get at other places” (St. John, 2000).

\section{Self Image and Identity}

Students with a strong sense of self and cultural identity are less likely to be vulnerable in an environment that may not be as welcoming to them (Chavous, Rivas, Green, \& Helaire, 2002). Having a positive and strong sense of identity may prevent feelings of not socially fitting in, which may also influence participation in social activities (Chavous et al., 2002). African American students that have a positive self-image and have confidence in their abilities have fewer self-doubts in their ability to attain their degrees in a potentially negative environment (Ervin, 2001; Gloria, Robinson Kurpius, Hamilton, \& Wilson, 1999). The most important attributes that African American students need in order to succeed are a strong sense of confidence, cultural pride, and deter- 
mination (Taylor \& Olswang, 1997). The women in this study each expressed a strong sense of personal identity and attributed that sense of identity to their experiences attending HBCUs. This is particularly true for Paulette who said,

I think it made me stronger in a lot of ways because I had never been in that environment you know where I was the majority, where I met smart Black people everywhere. In all of my classes they were, well in my department there were no majority Black professors, but I did get to see a lot of Black professors. When growing up I can count you know, on my hands the number of Black teachers that were in my county. So it did do a lot, I think, to help my self-confidence and what I felt about people as a whole, which helps you think of yourself and what you can do.

According to Keisha, her undergraduate experience helped her "to find that identity [as to] where I have a purpose in my life and to actually seek that purpose out." This is confirmed by Shavanna's statement that "it helped me to develop character and enhance who I am and better understand how I fit," and by Kerry's statement that "it helped me develop socially as a person in tremendous ways." Having such a strong sense of who they are, as shown in these statements, they are less likely to allow others to minimize their potential. Their undergraduate experience was about more than academics. It was about maturing the whole person and connecting their students desires with their academic abilities (Allen et al., 2007; Perna et al., 2009).

\section{The Culture at PWIs - A Little Chilly}

For African American female students who have attended HBCUs, graduate school at a large research institution may be daunting. The argument is that at the graduate level academic culture, which influences the success of graduate students (Gardner, 2007), invests little in personal involvement: it is not expressive, but analytical, abstract, symbolic (Hammack, 2001; Ibarra, 2001) and filled with ambiguity in regards to program guidelines and expectations (Gardner, 2007). Some may call it indifferent or chilly, but such an atmosphere does not encourage the giving of advice to new students and it sets an expectation that students work independently-or in isolation—on their studies (Morelle, 1996).

Coming from an environment that has been described a nurturing family environment Keisha describes the culture of her graduate school as "cordial." Kerry described herself at school as being "totally alone" during her first year, while Paulette said, "They did not do anything to make me want to stay here." Shavanna was complimentary with her comments that "[My] department is not hostile and the people within the department are friendly." These statements can be compared with the comments about "home," "family atmosphere," and "everyone is special" used in reference to the climate at HBCUs.

\section{Interactions with Faculty at PWIs}

Faculty relationships are a double edge sword for women in science. It is expected that such relationships will be close since they are crucial to the success and progress of the students as a graduate students and a professional (Etzkowitz, Kemelgor \& Uzzi, 1994), but that is not always the case. Since there is such a large number of male faculty to female student ratio in every field, particularly female of color, there are (at times) faculty members who are the leaders of discrimination because they have low expectations and stereotypical perceptions of African American and female students (Kobrak, 1992; Suarez, Balcazar, Orellana-Damacels, Portillo, Rowan, \& Andrews-Guillen, 2003). This is unfortunate since faculty members provide the reality of what is expected of the students in the classroom. Faculty have the power to make the classroom environment inclusive for all of the students through their demeanor, expectations, and curriculum. Inclusiveness was definitely not the case for Rochelle. She said that she felt as if she did not be- 
long: "No one really pays attention to me. I went from [having an] open, concerned and caring professor to not as opened and friendly."

Inaccessibility and less than positive responses to students by faculty may be perceived by African Americans as discriminatory, which may leave the student wondering what is expected of them academically (Kobrak, 1992; Saenz, Marcoulides, Junn, \& Young, 1999). This issue is of particular importance since low expectations of African Americans students by their instructors may have a negative impact on the students' self esteem (Kobrak, 1992). Fortunately that was not the case for Shavanna, who said, "I definitely feel like my professors have done their part in teaching/explaining the material that will be covered on the exams; I just have to make sure I do my part. If you do your part they are willing to help.” This comment is in sharp contrast Victoria, who states, "Teachers do not teach, they lecture and leave. If you need help you have to go to a TA."

\section{Interactions with Peers at PWIs}

Interactions with their White peers may at times also be ambivalent. The White peers of these students are generally cordial but had no clue about African American culture, other than what they had seen on television. The women in this study found themselves being their peers' and others' only window to a group of people and a world that is seemingly different from their own. Kerry (the only African American female in the graduate math department at that time) recalls an incident when

the Director of Graduate Studies [at that time] called me in his office: 'I just want to check on you and see how you are doing.' Then he said, 'this is really your first time being around White people.' It kind of rubbed me the wrong way but said, 'No, I have been around White people before.' He tried to clean it up and say well, 'I guess you have been in stores and stuff, you're right.'

For Victoria there was just a very large disconnect based on her statement that "you realize that you talk to these people but they don't know you and never will be able to know you."

With little or no interaction with peers who share the same values and outlooks on life, minority students are not exposed to interpersonal relationships that bring about reassurance and confirmation that "all is well." This was exactly the case for Keisha (the only African American female graduate student to enter in the math department in that year), who said, "Some people don't speak and so I'm not as comfortable speaking with everyone anymore because I don't like not getting a response. I talk to my officemate. I see her all the time.” This lack of reassurance and confirmation of abilities may cause minority students to feel less prepared. This is also the case for Shavanna (one of six African American graduate students in math) who said, "The other grad students are helpful and they provide feedback about teachers and materials" but they do not provide much social interaction beyond that." So, when relationships are formed it is primarily with others that are of the same race/ethnicity because of similar cultural values (Ellis, 2001; Herzig, 2004). These created communities allow students to express their concerns and create a safe place for themselves (Ellis, 2001). For Shavanna, who was the only African American female student that began the program, said,

I am a part of the Association for the Concerns of African America Graduate students. This is a group that offers an opportunity for African American graduate students to network with each other, participate in campus activities, socialize, and discuss issues that affect us on campus and in society. This is a great way to connect with others who understand what you go through on a daily basis in some form or fashion. 


\section{Academic Preparedness}

The acquisition of knowledge is imperative for students' success. This skill is influenced by the students' sense of belonging (Ellis, 2001). In order to conquer the adjustment process successfully, students need to have the ability to grasp the skill and knowledge that is being presented. Alienation from faculty and peers, as described above, may lead to students not being comfortable enough to ask questions, attend seminars, or request needed help to understand the subject matter (Ellis, 2001).

Academics were a challenge for the students in this study. They had to deal with the faculty's perception of their ability to do the work, as well as their own misgivings as to the amount and difficulties of the work. "My instructors did not notice me until they saw my test grades and knew that I could do the work," noted Rachelle. They all felt that they were behind and not grasping the material as easily as they would have liked to. As Shavanna said,

Everyone is intelligent with different backgrounds and knowledge. I did have to catch up in order to get the some of the material. It is imperative that I study independently and with study groups on a regular basis and sometimes I also go to see my professors for additional assistance.

Despite feeling that they were either at the bottom or the middle of the scale of knowledge, they progressed while many of their peers who began the graduate program with them did not. For Victoria she:

stressed about grades because you can only have an A or B and there were a few courses that I struggled with the whole time. [As a result] I got a tutor. He was from Thailand and he was really good. I worked with him a lot. [This was really important since], in my first semester I was slightly behind I had to work really hard to get it. Now I am slightly ahead while other students are still taking undergraduate courses.

For Paulette there was a realization that you have to learn it and know it and not just memorize it for a test anymore. "I think that happened with a lot of people, no matter what schools they went to. I struggled and I felt as if I was at the bottom but I am still here and others are leaving."

\section{Strategies for Success}

Goal commitment, which contributes directly to self-efficacy, is the most important predictor of success (Leslie, McClure, \& Oaxaca, 1998). Students who are not fully committed to their goal are less likely to tolerate unpleasant situations and leave the program. Students who are fully committed to their goal are likely to contend with the adverse conditions and achieve their goals (Leslie et al., 1998). Many of the women in this study admitted to the thought of leaving their programs. They wondered if the university or the degree was what they were supposed to be doing. However, with a strong commitment to their goals, these women conquered both internal and external barriers in order to succeed.

Having considered the possibility of leaving school, Paulette put it best when she said, "I refuse to give up just because it is hard." They all refused to give up and they all decided to stay. For Shavanna it is all about adjusting, "You have to adjust. You have to make the effort to allow people to get to know you." As Kerry stated, "The faculty may not be impressed with my performance but they respect me for my resilience”. This sentiment was shared among all of the students in this study.

Instead of becoming shrinking violets the women in this study became determined to make their presence known; this was done by speaking with their instructors and TA's and by hiring tutors in order to assist them in understanding the course work. Each individual also made a conscious de- 
cision to curb their behavior towards their peers, to become more business-like, and to interact in such a manner that garnered what they needed in order to survive their programs. "I carry myself in a more professional manner [sic]," is what Keisha stated, and Victoria commented that "At this school I try to carry myself like I'm smart and I'm determined and prove that I can do anything anybody else is doing, but I also don't share everything about myself."

\section{Summary}

Goal commitment and determination are imperative for these women in completing their doctorate degrees. The women in this study expressed much fortitude about receiving their doctorate; they continue to forge ahead in spite the obstacles they have faced (Schwartz, Bower, Rice, \& Washington, 2003). Basically, they refused to give up despite not fitting the perceived norm of what it is to be a scientist or a mathematician. They all, at some point, had self-doubts and withdrew from others but in order to move on they knew that they had to take the first step. They also responded by becoming involved in activities on and off campus that provide an alternative means for connecting with their peers, which resulted in them becoming more visible and making their presence known. They spent time with other graduate students, in varying disciplines, who provided them safe spaces to express their thoughts and concerns. These women also risked their vulnerability and asked faculty members for help. Asking for help from a faculty member was a turning point for Paulette (the only African American female student in her cohort) because due to her pride, her isolation was not in her best interest. As Paulette said,

I finally broke down and asked for help. It was a very humbling moment for me. I don't know why it took me so long to go to my advisor. Well, yes I do; because I don't like to ask anyone for help; too much pride. I have been struggling with my work and everything else since I got here. But it was ok. He said he understood why I was frustrated and he did think that I was working hard. He also said that he had seen a lot of improvement in my work but there were still some areas that I needed to work on. He said that he could work with me and we could figure out something together. To make a long story short, well shorter, I feel better about the whole school situation now. My body even feels better. I am so glad I finally talked to him. Wish I would have done it a year ago.

The women in this study also became involved in departmental activities and took the time to get know others. Some became involved with women or minorities in science organizations on campus. Particularly, it was imperative for Shavanna to become more visible. "Being the only African American first year student I go to events and put myself out beyond academics," she said. It is obvious that Shavanna has taken responsibility of her actions and her adjustment. One of the biggest adjustments for Shavanna has been going from being highly involved at her undergraduate institution to being so academically focused at her new institution. In order to combat this she began to participate in various activities around campus and in her department. "I have been spending a lot more time on campus making myself more visible in the department and in the community.” These groups allowed the students to express their concerns about their department, research, and personal life (Ferreira, 2002). These interactions helped each student establish her own climate of collaboration to offset the attitude of indifference encountered in her department cultures.

From the insight, as a result of the stories told by these young women, it can be concluded that the transition to graduate school, for this select group of women, has been problematic at best. Graduate school culture was a shock for them, in many cases, and these women became culture brokers of Black culture to many of their peers. As a result many of these women admit to the thought of leaving program. They lay awake more than a few nights and wondered if this school or this degree is what they are supposed to be doing. They realized that their academic experiences are opportunities that are only afforded to a few. 


\section{Conclusion}

The choice to attend graduate school for these women was career driven, as none of them wanted to be "lab rats". They want to have control over their futures. They all believe that education is imperative for their future success as scientists, mathematicians, and as professors. They also knew that they were entering environments (schools) that were different (in terms of people, research, and institutional funding) from their undergraduate institutions. They had taken the required courses, participated in science / math related programs, and had participated in internships. The women in this study all received a great deal of funding for their graduate education, which was essential to them attending school and the school of their attendance.

What they did not expect was the level of challenges that they faced, the first being academically. They all felt that they were behind and were not grasping the material as easily as they would have liked to. Although some professors were more helpful than others, on some level, they felt that disconnect between their professors and themselves that caused many of them to not ask for help and just study in isolation by themselves. Their interaction with their respective peers ranged from non-existent to helpful. Research has proven that relationships and the acquisition of knowledge within the first two years is crucial as to whether or not a students complete their program and to what kind of career they have thereafter. Having considered the possibility of leaving school they decided to make their presence know, speak with their instructors and TA's, and hire tutors in order to understand the course work. They all made a conscious decision to moderate their behavior with peers and to become more business like and interact in such a manner that they get what they needed to survive. The African American females in this study knew that their long-term goals and future is much more than the discomfort that they were feeling while attending graduate school.

\section{Discussion}

You cannot expect these women or anyone to separate their undergraduate experience from their graduate experience. The one thing that has influenced their resilience is their reflection of their undergraduate experiences, which provided them with a strong sense of security. Being able to recollect their interactions with so many positive African American people (on all levels) and the can do spirit from their undergraduate years, which was inspirational in their attending graduate school in the first place, was imperative since the transition to graduate school was problematic at best.

Graduate school culture was a shock for them, in many cases, and these women became isolated from faculty and their peers and questioned their own abilities. This is a quite dissimilar to the feeling that many of these women felt at their undergraduate institution. Graduate education is based on mastering the techniques of the discipline with a focus on the academic norms and behaviors (Herzing, 2004; Ibarra, 2001). They did not feel inspired and strengthened by their graduate school experience; instead that environment challenged their identities and caused them to feel boxed in by the behavioral norms of their respective fields (Ibarra, 2001). Fortunately for these women, they have their undergraduate experience to recall and reflect upon. On more than one occasion these women have had to refer to that recent past in order to strengthen their sense of self so that they can continue on. Kerry made a conscious effort to stay positive.

I had to be very proactive in preventing it from damaging my self-image. I mean; I definitely can see how it could have had negative effects on my self-image, just because of my initial experiences of being sort of invisible. That could have done it. I felt like at [my graduate institution] I'm always trying to prove myself. It's just a very different experience. 
For Victoria, having to change her behavior has led her to believe that she has to work twice as hard, often being misunderstood, and feeling like she is alone. More specifically, Victoria said,

I am feeling like I have to bust my ass to get some prominent data collected. I don't want anyone, especially my research advisor feeling like I am not working hard enough. I have a slight fear of being labeled the lazy, unintelligent, or rude/angry Black girl from the HBCU. But after a while you realize that those things don't matter. Just because they went to a majority White school doesn't meant that they learned anything different from you. I feel most of the time that I am so different from everyone here and really alone.

From early on, the purpose of this piece has been to examine the transitional experiences of six African American female students from undergraduate study at Historically Black Colleges and Universities to graduate education in math and chemistry at Predominantly White Institutions. They are transitioning from being undergraduate students to graduate students and undergoing the process of ethnic identity formation as women and scientists. It is worth noting again that each woman's graduate experience is crucial to her academic and career success. During this socialization process values are the salient concept in the multiple roles that these women play and the questions they must answer: Can I do this? Do I want to be a graduate student? Do I want to do this work? and Do I belong here? (Austin, 2002; Teske \& Nelson, 1974; Tinto, 1993). This is particularly important since graduate school experiences are unique in that throughout the progression and persistence of the person's program the student transforms from a student to a colleague at the time of completion. As their professor becomes their colleague their relationships with their professors becomes very instrumental in determining the kind and type of work the students attain. Over time as psychological and contextual factors change the answers to these questions and each person's ethnic identity may also change. This dynamic construct of ethnic identity and change evolves based on the socialization experiences of the choices, behaviors, beliefs, values, and norms that characterize the community to which the person belongs (Phinney, 2003).

\section{Suggestions}

Students that are not well integrated, socially or academically, into their respective departmental communities and cultures are likely to leave graduate school (Herzig, 2004). Institutions of higher education are distinct establishments of history and culture, and that same culture and history may not be conducive to the success all of students in attendance. Increasing the representation and retention of minority women in the sciences involves acclimating and increasing their positive experiences with those cultures. This occurs by making changes on all levels, including in the attitudes of the scientific community and society, in admissions and hiring practices, and in the perception of minority women scientists across all areas of higher education (Sakai \& Lane, 1996). Some specific and immediate changes that could be implemented are highlighted below.

Integral relations with HBCUS and major research institutions (PWIs) may prove to provide a more seamless transition from undergraduate to graduate school for their outgoing students. Graduate Institutions (PWIs) need to consider the effects of campus and department cultures on the female students of color. A student, who is either the only women, or the only African American, or the only member of both groups may initiate feelings of discontent and isolation from the very beginning of her graduate school experience. Having peers that look like them and that have similar interests was very important to the women in this study as they went through their programs. In terms of admissions, an increase of one of two women of color at a time may seem very small, but it makes a tremendous difference to students that would otherwise find themselves alone.

Departmental in-service workshops at PWIs could provide a venue for the concerns of underrepresented students to be discussed. Workshops of this nature could provide both administrators and 
faculty insight into the pre-conceived ideas these students have about graduate school and help identify means to orient students to their new environment. Faculty could be motivated to take a more proactive role in creating a more welcoming atmosphere for the students and thus foster a smoother transition. Student affairs practitioners are often already familiar with identity and student development theory, which could be extremely helpful in developing these types of departmental in-service training programs.

A bridge program at PWIs (Chubin, May, \& Babco, 2005; Maton \& Hrabowski, 2004) for both students and faculty would also assist in a smooth transition during the crucial first years. A program of this manner would allow all of the new students to get to know one another and help build the peer relationships that tend to be crucial to a successful outcome (Chubin et al., 2005; Maton \& Hrabowski, 2004). Being able to navigate one's program is just as important to success as being able to acquire academic knowledge, and having strong relationships with both peers and faculty is instrumental in learning how one's department and school work.

Accordingly, mentorship is also very important. Each new student should be assigned a peer mentor, a higher-level graduate student to assist him or her in adjusting. These mentors should be properly trained with faculty oversight and be willing to share their insights and tips about the program, the school, and how to navigate both.

Vigilance needs to be taken in order to increase the number of African American women in the sciences on all levels of academia and in industry. Attention must also be paid to the perception of a successful scientist so that it is an inclusive concept. While the ultimate goal for representation is parity with White males, who are so dominant in the STEM fields of study, even a small increase in the number of African American women at the faculty level can change the social dynamics for the African American women students who now grace the halls of higher education (Jaschik, 2010), where few if any have walked before.

\section{Final Remarks}

All institutions should recognize the complexity of the issues that hamper the success of minority graduate students (Fields, 1998). The persistence of minorities in graduate science programs is dependent on a supportive learning environment where there is a shared understanding of faculty, students and administrators alike of the purposes of the program (Anonymous, 1999). Recognizing that changes and programs that work at one institution may not work in another. Diversity, no matter the institution, should be considered a resource and not a problem. But, as human nature has it, administrators may not have fully considered the challenges and solutions that could best assist these students, who begin with an added challenge since racial and gender biases often render them less powerful than other graduate school students from the dominant culture (BeokuBetts, 2004).

\section{References}

AAUP. (1995). The historically black colleges and universities: A future in the balance. Academe, 81(1), 49-57.

Allen, W. R., Jewell, J. O., Griffin, K. A., \& Wolf, D. S. S. (2007). Historically black colleges and universities: Honoring the past, engaging the present, touching the future. The Journal of Negro Education, 76(3), 18.

Amenikhienan, C., \& Kogan, L. (2004). Engineering students' perceptions of academic activities and support services: Factors that influence their academic performance. College Student Journal, 38(4), 18.

Anonymous. (1999). Completing the Ph.D.: What faculty, departments, and students can do. PS: Political Science \& Politics, 32(2), 266. 
Austin, A. (2002). Preparing the next generation of faculty. The Journal of Higher Education, 73(1), 27.

Berger, J., \& Milem, J. F. (2000). Exploring the impact of historically black colleges in promoting the development of undergraduates' self-concept. Journal of College Student Development, 41(4), 381-394.

Beoku-Betts, J. (2004). African women pursuing graduate studies in the science: Racism, gender bias, and third world marginality. NWSA Journal, 16(1), 20.

Berry, J. W. (1997). Immigration, acculturation, and adaptation. Applied Psychology: An International Review, 46(1), 5-34.

Bethea, G. (2005). Graduate school kicks off new PhD. Retention and attrition efforts with luncheon and charge from Provost Richard English. Washington, D.C.: Howard University.

Brown, M. C., II, \& Davis, J. E. (2001). The historically black college as social contract, social capital, and social equalizer. Peabody Journal of Education, 76(1), 31-49.

Burgess, D. R. (1997). Barriers to graduate school for minority-group students. The Chronicle of Higher Education, 44(7), B7-B8.

Chavous, T., Rivas, D., Green, L., \& Helaire, L. (2002). Role of student background, perceptions of ethnic fit, and racial identification in the academic adjustment of African American students at a predominantly white university. Journal of Black Psychology, 28(2), 234-260.

Chubin, D. E., May, G. S., \& Babco, E. L. (2005). Diversifying the engineering workforce. Journal of Engineering Education, 94(1), 73-86

Ellis, E. (2001). The impact of race and gender on graduate school socialization, satisfaction with doctoral study, and commitment to degree completion. The Western Journal of Black Studies, 25(1), 16.

Ervin, K. S. (2001). Multiculturalism, diversity, and African American college students. Journal of Black Studies, 31(6), 764 - 776.

Etzkowitz, H., Kemelgor, C., \& Uzzi, B. (Eds.). (1994). Barriers to women in academic science and engineering. Baltimore, MD: Johns Hopkins University Press.

Feldman, D. C. (1981). The multiple socialization of organization members. Academy of Management Review, 6(2), 10.

Ferreira, M. (2002). The research lab: A chilly place for graduate women. Journal of Women and Minorities in Science and Engineering, 8(1), 85-98.

Fields, C. D. (1998). Gems of wisdom: Avoiding derailment on the doctorate track. Black Issues in Higher Education, 15, 3.

Fries-Britt, S., \& Turner, B. (2002). Uneven stories: Successful black collegians at a black and a white campus. The Review of Higher Education, 25(3), 315 - 330.

Gardner, S. K. (2007). "I heard it through the grapevine": Doctoral student socialization in chemistry and history. Higher Education, 54(5), 18.

Gloria, A. M., Robinson Kurpius, S. E., Hamilton, K. D., \& Wilson, M. S. (1999). African American students' persistence at a predominantly white university: Influences of social support, university comfort, and self-beliefs. Journal of College Student Development, 40(3), 257 - 267.

Hamilton, K. (2001). Doctoral dilemma. Black Issues in Higher Education, 4.

Hammack, F. (2001). Review of Beyond affirmative action: Reframing the context of higher education, by Robert Ibarra. American Journal of Education, 109(3), 307-400.

Herzig, A. H. (2004). Becoming mathematics: Women and students of color choosing and leaving doctoral mathematics. Review of Educational Research, 74(2), 171 - 214.

Ibarra, R. (2001). Beyond affirmative action: Reframing the context of higher education. Madison: University of Wisconsin Press. 
Jaschik, S. (2010, March 11). Race matters. Inside Higher ED.

Kim, M. M. (2002). Historically black vs. white institutions academic development among black students. The Review of Higher Education, 25(4), 385-407.

Kim, M. M., \& Conrad, C. F. (2006). The impact of historically black colleges and universities on the academic success of African-American students. Research in Higher Education, 47(4), 29.

Kobrak, P. (1992). Black student retention in predominantly white regional universities: The politics of faculty involvement. Journal of Negro Education, 61(4), 509-530.

Leggon, C. (2003). Science, technology and inequalities: Women of color. Paper presented at the Knowledge \& Discourse: Speculating on Discipline Futures.

Leslie, L., McClure, G., \& Oaxaca, R. (1998). Women and minorities in science and engineering. The Journal of Higher Education, 69(3), 239 - 277.

Maton, K., \& Hrabowski III, F. (2004). Increasing the number of African American PhDs in the sciences and engineering. American Psychologist, 59(6), 547 - 556.

Mays, B. E. (1942). The role of the Negro liberal arts college in post-war reconstruction. The Journal of Negro Education, 11(3), 12.

McElfresh, A. (2005). Graduate dropout problems increase: Project plan calls to increase retention. LSU Reveille.

Morelle, V. (1996). Computer culture deflects women and minorities. Science, 271(5257), 2.

NSF. (2009a). S\&E bachelor's degrees awarded by leading institutions, by race/ethnicity of minority graduate: 2003-07. Women, minorities, and persons with disabilities in science and engineering. Washington, DC: National Science Foundation.

NSF. (2009b). Top baccalaureate institutions of black S \&E doctorate recipients: 2003-07. Women, minorities, and persons with disabilities in science and engineering. Washington, DC: National Science Foundation.

Ong, M., Wright, C., Espinosa, L., \& Orfield, G. (2011). Inside the double bind: A synthesis of empirical research on undergraduate and graduate women of color in science, technology, engineering and mathematics. Harvard Educational Review, 81(2), 37.

Perna, L. W., Lundy-Wagner, V., Drezner, N., Gasman, M., Yoon, S., Bose, E. (2009). The contribution of HBCUS to the preparation of African American women for STEM careers: A case study. Research in Higher Education, 50(1), 24.

Phinney, J. (2003). Ethnic identity and acculturation. In K. Chun, P. Organista, \& G. Marin (Eds.), Acculturation (pp. 63-81). Washington DC: American Psychological Association.

Saenz, T., Marcoulides, G. A., Junn, E., \& Young, R. (1999). The relationship between college experience and academic performance among minority students. The International Journal of Educational Management, 13(4), 199-207.

Sakai, A. K., \& Lane, M. J. (1996). National Science Foundation funding patterns of women and minorities in biology. Bioscience, 46(8), 621-626.

Schwartz, R. A., Bower, B. L., Rice, D. C., \& Washington, C. M. (2003). Ain't I a woman, too?: Tracing the experiences of African American women in graduate school. Journal of Negro Education, 72(3), 252 - 268.

Seidman, I. (1998). Interviewing as qualitative research (2nd ed.). New York: Teachers College Press.

St. John, E. (2000). More doctorates in the house. Black Issues in Higher Education, 17(10), 38-44.

Suarez-Balcazar, Y., Orellana-Damacela, L., Portillo, N., Rowan, J., \& Andrews-Guillen, C. (2003). Experiences of differential treatment among college students of color. The Journal of Higher Education, 74(4), 428 - 444. 
Subramaniam, B., \& Wyer, M. (1998). Assimilating the "culture of no culture" in science: Feminist intervention in (de) mentoring graduate women. Feminist Teacher, 12(1), 12.

Taylor, E., \& Olswang, S. (1997). Crossing the color line: African Americans and predominantly white universities. College Student Journal, 11-18.

Teske, R., \& Nelson, B. (1974). Acculturation and assimilation: A clarification. American Ethnologist, 1(2), 351 - 367.

Tinto, V. (1993). Leaving college: The causes and cures of student attrition (2nd ed.). Chicago: University of Chicago Press.

Turner, C. S. V. (2002). Women of color in academe: Living with multiple marginality. The Journal of Higher Education, 73(1), 74-93.

Turner, C. S. V., \& Thompson, J. R. (1993). Socializing women doctoral students: Minority and majority experiences. The Review of Higher Education, 16(3), 355 - 370.

Van Maanen, J. (1983). Doing new things in old ways: The chains of socialization. In J. L. Bess (Ed.), College and university organization (pp. 211-246). Association for the Study of Higher Education.

Ward, C. (1996). Acculturation. In D. Landis \& R. Bhagat (Eds.), Handbook of intercultural training (pp. 124-147). Thousand Oaks: SAGE Publications.

Weidman, J. C., Twale, D., \& Stein, E. L. (2001). Socialization of graduate and professional students in higher education (No. 28). Washington, DC.

\section{Appendix: Interview Protocol}

\section{Background Information}

1) Do you consider your family and life as one of middle, working, or upper class?

2) How did you become interested in this discipline (math, science, or engineering)?

\section{Undergraduate Information}

3) What undergraduate institution did you attend and why?

4) What did you expect of the institution prior to enrolling?

5) How would you explain the culture (socially and academically) and its affect on your matriculation?

6) Tell me about any stressful moments (academically and socially) and how you dealt with them?

7) Explain your courses that were directly related to your discipline (their rigors, your impression of them, and whether or not they prepared your for your future)?

8) Were there any experiences or events that either strengthened or made you question your readiness for graduate school and a career in this area?

9) Tell me about your relationships with peers and faculty members?

10) What did your advisor do to encourage you in your endeavors to attend graduate school and pursue your career?

11) How would your undergraduate advisor describe you and your fitness for the field or math and science (socially and academically)? 
12) Were you encouraged to conduct research and what was the procedure to go about securing research experience?

\section{Graduate School Information}

13) Why did you choose to attend graduate school?

14) Why did you choose this particular school?

15) What were / are your expectations of this institution prior to attending it?

16) What is / was the culture like on and around campus?

17) Do you know the percentage of graduate students that are African American?

18) Describe your department and its culture?

19) What has been some of the most stressful moments for you since you have been here?

20) Did you choose your advisor or was your advisor assigned to you?

21) How do you feel about that advisor and his/her interactions with you?

22) Are you performing any type of TA or RA, if so, what kind?

23) If working in the lab, who is your lab director?

24) Is your lab director and advisor the same person?

25) How did you obtain the position?

26) What level of lab work are you performing?

27) Are you the only student in the lab?

28) What is the atmosphere like in the lab?

\section{Undergraduate v. Graduate}

29) What are the similarities and differences in the culture and the way students treat each other on campus and within your department?

30) Explain how the system (at both your undergraduate and graduate institutions) work (how to go about getting things done) and the pros and cons of each?

31) How were you treated by faculty and staff at your undergraduate institution and what about that treatment is the same or different at your graduate institution?

32) Are there any social images you feel that you have to either live up to or disprove?

33) Have you faced any instances of discrimination, if so, how did you deal with it?

34) Where you involved in any student organizations as an undergraduate and are you / have you been involved in any as a graduate student?

35) How has those organizations assisted you in the transition from one institution to the other as well as going from undergrad to grad student?

36) Are the ways of coping with stressful situations different in graduate school than they were while you were attending your undergraduate institution? 
37) Do you notice a difference in attitudes and behaviors in the African American students at your undergraduate and graduate institutions?

38) How has (do you see) your attendance at both institutions as being beneficial to your future as a person and as a scientist?

\section{Future}

39) How do you view your future career choice and path?

40) What is your perception of the social aspects of the career path chosen?

41) Do you believe that you can fit into the social aspects of this career?

42) What advice what you provide to other students that would like to follow your path?

\section{Biography}

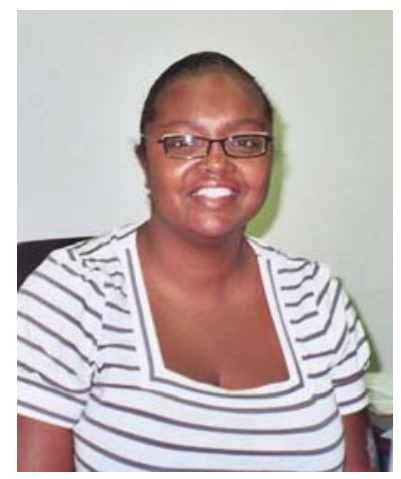

Joretta Joseph has a diverse academic background with a Bachelors degree, a Masters in Business Administration from two HBCUs and a Doctorate of Education degree from a PWI. Currently she works at the National Physical Science Consortium, a national educational nonprofit organization that administers fellowships for individuals, particularly women and people of color, seeking doctorate degrees in the physical sciences, as the Program Administrator and Graduate Advisor. In addition to that she mentors middle and high school youth. 